\title{
Multiple Dimensions of Effective Assessment in Graded College English Teaching Classroom*
}

\author{
Kang Liu \\ Sichuan University of Arts and Science, Dazhou 635000, Sichuan, China \\ Xiaoli Gan \\ Sichuan University of Arts and Science, Dazhou 635000, Sichuan, China
}

\begin{abstract}
Teaching assessment refers to the process of assessing the teaching effect and implementation of the teaching goal, it aims to make corresponding value judgment through systematic detection and assessment of teaching activities according to certain teaching criteria. An effective teaching assessment not only brings teachers feedback and improves the teaching administration, but also provides students with an effective means to optimize the learning strategies to achieve better learning efficiency and desired effects. So a comprehensive and accurate assessment is of vital significance to propel the course goals into accomplishment. In college English graded teaching practice, it is prerequisite to adhere to the assessment principle of development and diversification of assessment dimensions in order to arrive at an effective classroom evaluation.
\end{abstract}

Index Terms - college English, effective teaching, graded teaching, assessment principles, dimensions of assessment

\section{INTRODUCTION}

Classroom is the forum where the teachers and students communicate with each other intellectually and emotionally. In classroom, teachers present science information and preach concepts of value, and students acquire knowledge, train skills and improve their own minds simultaneously. Generally speaking, classroom instruction is a process to arouse students' motivation and help them to arrive at the teaching goals with proper teaching methods. So classroom instruction is the central part in the whole teaching process, which is the important guarantee of achieving teaching objectives (Wang \& An, 2012). In order to monitor how well teaching objectives go, we employ strategies of classroom assessment into teaching practice. Teaching assessment itself is fundamentally a judgement of value, involving teaching, learning, teaching quality and spiritual effect ( $\mathrm{Lu}$, Liang \& Shen, 2012), it is to use a wide variety of methods or tools to measure and evaluate the teaching qualities, learning progress, or educational needs of learners. Only by means of assessment, can teachers identify students' strengths as well as weakness in study. Meanwhile, as an ongoing process through teaching activities, assessment can not only motivate students in study and help adjust the learning strategies to improve their learning efficiency, but also bring about backwash effects to teachers so as to purposefully regulate teaching activities and ensure the teaching quality.

The course of college English, as a required basic part of higher learning, aims to develop students' ability to use English language, at the same time improve their autonomously learning ability and enhance their general cultural awareness and comprehensive artistic appreciation, so as to satisfy the needs of social and individual development (Ministry of education, 2017). Considering personal difference and various individual needs as well as the regional imbalance of education, college English follows the principle of graded teaching and guidance for different levels of students according to their aptitudes. As a practical teaching way, college English graded teaching centers on the course's global objectives of accumulating students' knowledge, broadening views of eyesight, improving critical thinking ability and molding characters (Han, 2012). In the practical teaching procedures, college English teachers undertake the tasks to provide appropriate studying materials, stimulate students' learning interest, work out the confusing problems, construct appropriate learning strategies and offer chances for students to make presentations of what they think and what they do (Shu, 2011). So assessments of college English class would be conducted from multiple perspectives, it can't be narrowed down to the means of pencil-paper testing of English language and language skills as before. A scientific college English classroom assessment, which can reflect the pros and cons of teachers' cognition and teaching behaviors, curriculum designs and students' learning behaviors, is supposed to be set up on the basis of testing methods and non-testing methods, it is objective, comprehensive and multidimensional.

\section{Theoretical Basis of EfFective College English Graded Teaching}

\footnotetext{
${ }^{*}$ Funded by Education \&Teaching Reform Programme of Sichuan University of Arts and Science (Program No: 2017JY12).
} 
Teaching is what the teacher inspires and promotes the students into doing. It works on three premises that the teacher can arouse the students' internal motives, designate the learning objectives and impart studying contents, and present what he teaches in a proper way. Classroom assessment aims to check the effective implementation of teaching objectives, therefore, teaching should firstly be genuine and effective practice so as to make sure of effective assessments.

\section{A. Definition of Effective Teaching}

The effective teaching is a dynamic concept, the connotation of which is enriched with the changing values of education and teaching theories (Huang, 2014). Influenced by American practical philosophy and behavioral psychology, the notion of effective teaching originated from the foreign educational scientific movement in the first half of twentieth century, claiming that education is more than an art, that it is a science grounded with scientific basis and objective research methods (Cui, 2001). So from then on, people began to focus attention on teaching procedures, behavioral conducts and teaching effects from the aspects of classroom observation and teaching assessment. But up to now, there still comes no fixed definition to effective teaching. Dunner \& Wragg (2005) stated that effective teaching is to teach students to acquire facts, skills, values and beliefs, what is more, it is a process that can be controlled and adjusted with objective assessment from teachers, students and administrators. The domestic scholar argued that effective teaching is a teaching concept conforming to teaching laws, which is characteristic with effect, benefit and efficiency (Yao, 2004). Personally speaking, effective teaching, as a teaching and learning practice, is supposed to contribute to students' physical, intellectual, mental or psychological development and progress. How well students make progresses in a period of study is the decisive criteria to judge whether the teaching practice is effective or not.

\section{B. Typical Theories of College English Graded Teaching}

In the 1980s, the great British educator, J. Harmer argued in his Balanced Theory of Foreign Language Teaching that, in order to achieve effective language teaching result, teachers should choose the teaching materials on the basis of analysis of what the students need to satisfy their demands (Ma, 2001). Almost in the same period, Vygotsky (1978), founder of the zone of proximal development (ZPD) put another theory that there is a gap between what a student can do independently and what he can potentially do with the help of a "more knowledgeable other", so the effective teaching and learning state is where students remain close to developing the new skill or knowledge with teachers' assistance and encouragement. To ensure that students are learning in the circle of their zone of proximal development, teachers are supposed to provide new curriculum for students to work slightly beyond their present skills. Graded college English teaching practice groups the students into different levels according to their individual difference of cognition, and teachers design and organize targeted classes for different levels, so that most students can be kept at the stage of Comprehensive Input (i+1) in terms of Input Hypothesis theory. In other words, the language which learners are exposed to should be just far enough beyond their current competence that they can understand most of it but still be challenged to make progress, the corollary to this is that input should neither be so beyond their reach that they are overwhelmed $(i+2)$ nor so close to their current stage that they are not challenged at all $(i+0)(B r o w n, 2001)$.

Graded teaching conforms to the law of human cognition and parallels with individual physical and psychological developments of students, it is apt to achieve good teaching results. So college English graded teaching is kind of effective teaching which is closely related to comprehensive competence of teachers, teaching strategies, students' motivation and autonomous learning abilities, curriculum design and teaching environment (such as the equipment of multimedia, administration of teaching etc). When it comes to evaluation of such teaching practice, assessment of it should start from the teaching objectives and syncretize multiple dimensions in the teaching practice, especially focus assessing attention on teaching dimension, learning dimension and design of curriculum (Wang \& An, 2012).

\section{EfFective Assessment PRinciples of College English GRADED TEACHING}

Classroom assessment differs from summative tests and other forms of student assessment because it is aimed at course improvement, rather than at assigning grades. The primary goal is to better understand students' learning situation and improve teaching quality. As an approach, it means that the more you know about what and how students are learning, the better you can plan to structure your teaching activities. As a set of techniques, classroom assessments can provide short-term feedback about learning and teaching process with low investment of time, and then encourage the view that teaching is a formative process that evolves over time with feedback. For students, more frequent use of classroom assessments helps to better monitor their own learning. So classroom assessment undoubtedly should be formative assessment, it follows the following principles.

\section{A. Student-centered Assessment Principle}

The student-centered assessment principle doesn't mean that everything is finished by students in the process of the assessment. When conducting classroom assessment of college English graded teaching, we check to see whether students are considered to be the main part in the teaching process. Is the class student-centered? Is the teaching objective aimed for students' intellectual and liberal developments? The student-centered class usually presents a picture that students are actively participating in the teaching activities rather than passively listening in to the teachers 
in class. What teachers do is to purposefully lead students to learn to learn how to demonstrate what students have thought and understood. Of course, the student-centered principle also requires that students are assessment users. Students are also one of important subjects of assessment, they are not only practitioners of self-assessment and peer assessment, but also the most important consumers of assessment results.

\section{B. Diverse-means Assessment Principle}

Assessment is a quite broad term covering efforts on the part of teachers or students to arrive at some conclusions on the ground of performance. A complete foreign language classroom assessment is composed of testing means and nontesting means (Genesee \& Upshur, 1996). Traditional teaching evaluation is narrowly confined to test, it constitutes quite salient subset within complete assessment system. As to recording the development of language skill and ability, non-testing means of assessment can produce much more washback effect. The popular forms of non-testing alternative assessments include portfolios, journals, conferences, observations and so on (Brown, 2007).

1. A portfolio is a "purposeful collection of students' work that demonstrates to students and others their efforts, progress, and achievements in given areas" (Genesee \& Upshur, 1996, p.99). Portfolios include essays, compositions, book reports, artwork, videotape or audiotape recordings of oral production. When using assessment of portfolio, teachers should specify the purpose, collect and return them promptly, and help students process the teachers' feedback.

2. A journal writing has the purposes of language-learning logs, grammar discussions, response to readings, selfassessment, reflections on attitudes and feelings about oneself. Journal writing is a dialogue between student and teacher, it affords a unique opportunity for a teacher to offer various kinds of feedback to learners. Using journals as assessment demands carefully specified, systematic approach, needing guidelines similar to those recommended for portfolios.

3. Conferencing has the advantage of allowing one-on-one interaction between teachers and students such that the specific needs of a student can receive direct feedback. Through conference, a teacher can assume the role of a facilitator and guide, the student can feel the teacher is an ally who is encouraging self-reflection in the intrinsically motivating atmosphere.

4. Assessment of observations can become systematic, planned procedures for real-time, almost surreptitious recording of student verbal and nonverbal behavior. An effective teacher has the ability to observe as they perform and know a lot about his students without ever administering a test or a quiz. With stable and continuous observations, his evaluation on the students has moderate practicality and reliability.

\section{Multi-objectives Assessment Principle}

It is true that the purpose of teaching evaluation can not only be limited to evaluation of subject content, more exactly examine whether or not developing certain value concepts. College English teaching classrooms not only impart language knowledge, develop language skills, but more importantly cultivate students' scientific thinking to acquire independent learning and researching skills, so that students have both language literacy and humanistic qualities. The objectives of college English classroom assessment covers knowledge accumulation, skill training and formation of value concepts (Huang, 2009). Therefore, in time of observing and evaluating a college English class, the conclusion of the assessment depends on whether the students' cognitive abilities get developed, whether language skills are trained and improved, whether learning strategies are cultivated, and whether emotional attitudes or humanistic spirits are positively formed and uplifted (Zhu \& Zhu, 2012).

\section{Assessment Dimensions in College English Graded Teaching Classroom}

The modern theory of constructivism advocates that knowledge and meaning is created on the basis upon learners' experiences rather than directional instruction from teachers. So Harmer (2000) insisted that effective English teaching has three tasks, engaging, studying and activating (ESA). In detail, the task of "engaging” means arousing students' learning interests and enthusiasm, which requires teachers of great language and teaching competence; "studying" refers to learning activities of the meaningful materials, and this involves students' learning strategies and choice of studying contents; and "activating" includes all of the language study practices, such as role-plays, debates, speech contests, etc. Richards (2001) argued that teachers' training experience and their teaching ability, the appropriate teaching patterns all together contribute to teaching effectiveness. From Harmer's ESA theory and Richards' opinion, we know teaching is a systematic and comprehensive project, the assessment of which develops from multiple dimensions.

\section{A. From Dimension of the Teachers' Qualities}

Classroom teaching activities reflect the teacher's comprehensive qualities in a certain degree. Cai Jiandong (2001) stated that teachers are supposed to have qualities of accumulating profound major knowledge, understanding laws of education, sharpening noble moral qualities and lofty spiritual realm so as to become a model for others. A college English teacher firstly must have excellent professional qualities, he should be proficient to hear clearly, speak fluently, read adeptly, write smoothly and translate freely. Additionally, he must command a lot of cross-cultural knowledge, linguistic knowledge and English teaching methodology. Secondly, college English teachers will improve 
understanding of the educational concepts, playing the roles as educators rather than pedagogues. A pedagogue only teaches knowledge and skills to make a living, while an educator focuses on the formation of students' personality, ideological and moral character, civilized behavior and individual all-round development. Thirdly, good political and ideological qualities are equally important for college English teachers. Foreign language teachers shoulder the mission of disseminating culture which is a concentrated expression of a country's politics, religion, customs and other aspects. It is required that teachers have a clear political standpoint to preach healthy and positive concepts of value to students. Fourthly, the author believes that teachers take serious attitudes towards the classroom teaching activities. With responsible attitudes, the teachers will make careful and scientific preparations, then they will also deal with classroom activities with full emotions and much passion.

\section{B. From Dimension of Course Design}

A course design is made up of teaching objectives and steps to achieve them. In a broad view, a course design is a purposeful, planned and structured systematic activity that produces teaching plans, curriculum syllabus and teaching materials. A successful course design is based on the careful analysis of the setting, the audience, and needs of the students (Richards, 2001). When designing a course, teachers should make clear what is the most important information students should learn and remember from this course (facts and other kinds of knowledge)? What are the most important ideas that students should understand after taking this course (theories, approaches, perspectives)? What are the most important skills that students should develop in this course (laboratory skills, problem-solving skills, creative skills, writing skills, etc.)? Narrowly speaking, the course design refers to a lesson planning which ensures how to make an implementation of a specific unit.

College English graded teaching in the author's university has grouped non-English majors into different levels, that is, the below-average level, average level, and above-average level, so all the college English courses should be fully individual-oriented, with consideration for the students from different starting points, so that students who start from lower levels will be well taken care of while students whose English is better will find room for further development. Moreover, the college English course design is to construct three different hierarchies with combination of required and elective courses aiming for improvements of language skills and English of specialty, so as to develop students' ability to use English little by little. Therefore, eye on college course assessment should find out whether the course design satisfies the hierarchic needs of students at different levels and whether the students make improvements in their abilities to use English after receiving appropriate knowledge and language skill training practices.

\section{From Dimension of Students' Engagement in Class}

In education, student engagement refers to the degree of attention, curiosity, interest, optimism, and passion that students show when they are learning or being taught, which extends to the level of motivation they have to learn and progress in their education. Generally speaking, the concept of "student engagement" is predicated on the belief that learning improves when students are inquisitive, interested, or inspired, and that learning tends to suffer when students are bored, dispassionate, disaffected, or otherwise "disengaged." (1) If we compare students' classroom engagement to a cube, the length of the "cube" refers to the time span of student engagement in class; the breadth of the cube stands for the number of attentive participants in class, and the depth can be thought to be "thinking level" of the engagement. As we know, the result to multiply the length, breadth and depth of the cube together just comes to the volume of the cube, which exactly reflects the students' initiative and enthusiasm to engage in learning. The larger the volume is, the better the students' classroom engagement proves to be. Of course, the factors of influencing student engagement and its implication are various and complicated. But anyway in a degree, the more actively students engage in class, the more successful a class shall be.

The student engagement in college English graded teaching classrooms can mirror the approperiateness of teaching materials, lesson designs, teaching methods and teachers' personal qualities (rich knowledge, moral nobleness, good language expression, affable character etc.). The class with active student engagement denotes that the teacher usually selects proper and interesting studying materials for different levels of the learners, connecting English learning with the students' majors, combining study of the abstract English language elements with language speakers' culture; it also indicates that the teacher works as a director rather than a broadcaster in class and manages to be familiar with the status quo of the class to design various classroom activities to mobilize the enthusiasm of different levels of students. Such class is characteristic with cooperative learning or group learning strategy, and students have more opportunities to listen, speak, read and write. At the same time, the learners lower their anxiety to perform in class because they can prepare in pairs or groups in advance, thus improving the learners' self-confidence, self-esteem and interest in language learning. On the contrary, the poor student engagement, with the symptoms of being absent-minded, uninterested, stressed and anxious, results from the boring class which is completely demonstrated in the monotous lecture-based teaching method. Teachers sweat to speak, and students struggle to keep awake because of insufficient or no interactions between two sides. Such kind of classes are usually of low validity.

Surely enough, there still exist other evaluation dimensions besides the above three main parts, such as the learning environment, the administrative regulations, etc. Dimensions of the assessment can also be called objects of assessment,

(1) https://www.edglossary.org/student-engagement/ 
in teaching practice if we hope to get an relatively objective assessment of the dimensions, it counts that multiple subjects of assessment, namely students, colleagues, experts etc., all together get involved in the evaluation of each dimension to comprehensively arrive at an effective assessment conclusion.

\section{SUMMARY}

Classroom teaching assessment is not only an integral part of the teaching process, but also a teaching monitoring mechanism. It has the functions of guidance, encouragement, feedback and adjustment for teaching and learning. The biggest goal of it is to improve teaching practice and promote students' development. In college English classroom, the earlier assessment has put much more emphasis on the teachers' language competence and organization of the class, and paid less attention to other factors. Just as a Chinese proverb goes, a handsome man conceals all ugliness (一俊遮 百丑). It seems as if a class is marvelous only if the teacher can speak good English. Actually, an effective classroom assessment derives from all-round evaluation of teacher's professional competence, curriculum design and student classroom engagement. In detail, the assessment bases on the indexes of the pre-class preparation, teaching morals, teaching objectives, classroom management, teaching methods, teaching content, course features and student development of knowledge, emotion and skills etc. Therefore, assessment of college English graded teaching classrooms should emphasize the diversification of assessing contents and the dynamic assessment process, attach much importance to the assessment of college English classroom teaching process and evaluate the learners' changes from the perspective of development, so as to realize the maximum benefits of assessment and achieve the purpose of promoting individual development and improvement.

\section{REFERENCES}

[1] Brown, D. (2001). Principles of Language Learning and Teaching: Krashen's Input Hypothesis. Beijing: Foreign Language Teaching and Research Press, 279.

[2] Brown, D. (2007). Teaching by Principles, an Interactive Approach to Language Pedagogy ( the 3rd edition). New York: Pearson Education Inc., 475-478.

[3] Cai, J. D. (2001). Constructing Assessment Index System of Normal University’s Classroom Teaching Qualities, Kaifeng: Henan University.

[4] Cui, Y. H. (2001). Effective Teaching: Ideas and Strategies. People's Education, 6, 46-47.

[5] Dunner, R. \& Wragg, T. (2005). Effective Teaching. New York: Routledge, 14.

[6] Genese, F. \& Upshur, A. (1996). Classroom-based Evaluation in Second Language Education. Cambridge: Cambridge University Press.

[7] Han, B. C. (2012). Reconstructing College English Teaching Objectives and Improving College English Curriculum System. Journal of Northwest Normal University, 1, 89-91.

[8] Harmer, J. (2000). How to Teach English. Beijing: Foreign Language Teaching and Research Press.

[9] Huang, Y. (2014). On Effective College English Classroom Teaching and Its Accomplishment Strategies. Teacher Education Forum, 12, 69-72.

[10] Huang, Y. Y. (2009). Probing into the Effectiveness of College English Teaching Classroom. Academic Forum, 11, 201-204.

[11] Lu, L. T., Liang, W. \& Sheng, Q. (2012). Reflection of Chinese Education Status Quo and Its Ways of Improvement. Journal of The Chinese Society of Education, 6, 43-47.

[12] Ma, S. H. (2001). On J. Harmer's Balanced Theory of Foreign Language Teaching. Foreign Language World, 2, $20-24$.

[13] Ministry of Education. (2017). Guidelines on College English Teaching. Beijing: Foreign Language Teaching and Research Press.

[14] Richards, J. (2001). Curriculum Development in Language Teaching. Cambridge: Cambridge University Press.

[15] Shu, D. F. (2011). On the Functions and Objectives of Foreign Language Classroom Teaching. Foreign Language and Their Teaching, 1, 5-8.

[16] Vygotsky, L. S. (1978). Mind in Society: the Development of Higher psychological Process. Boston: Harvard University Press.

[17] Wang, B. L. \& An, L. (2012). Briefly Discussing College English Classroom Assessment Criteria. Foreign Language World, 3 , $42-50$.

[18] Yao, L. M. (2004). Briefly Probing into the Connotation of Effective Teaching. Modern University Education, 5, 10-13.

[19] Zhu, J. X. \& Zhu, C. G. (2009). On the Reform of China's English Classroom Teaching Assessment, Education Research Monthly, 6, 68-69.

Kang Liu, a visiting scholar in U.S., is currently a lecturer of English at School of Foreign Languages, Sichuan University of Arts and Science, Dazhou, China. His research interests cover English teaching, culture of English-speaking countries.

Xiaoli Gan, a visiting scholar in U.S., is currently an associate professor of English at School of Foreign Languages, Sichuan University of Arts and Science, Dazhou, China. Her research interests cover English teaching. 